\title{
Plasticity, Morphology and Distribution in Twelve Lakeshore Plants
}

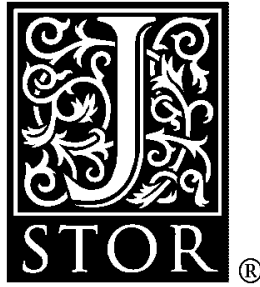

Scott D. Wilson

Oikos, Vol. 62, No. 3. (Dec., 1991), pp. 292-298.

Stable URL:

http://links.jstor.org/sici?sici=0030-1299\%28199112\%2962\%3A3\%3C292\%3APMADIT\%3E2.0.CO\%3B2-9

Oikos is currently published by Nordic Society Oikos.

Your use of the JSTOR archive indicates your acceptance of JSTOR's Terms and Conditions of Use, available at

http://www.jstor.org/about/terms.html. JSTOR's Terms and Conditions of Use provides, in part, that unless you have obtained prior permission, you may not download an entire issue of a journal or multiple copies of articles, and you may use content in the JSTOR archive only for your personal, non-commercial use.

Please contact the publisher regarding any further use of this work. Publisher contact information may be obtained at http://www.jstor.org/journals/oikos.html.

Each copy of any part of a JSTOR transmission must contain the same copyright notice that appears on the screen or printed page of such transmission.

The JSTOR Archive is a trusted digital repository providing for long-term preservation and access to leading academic journals and scholarly literature from around the world. The Archive is supported by libraries, scholarly societies, publishers, and foundations. It is an initiative of JSTOR, a not-for-profit organization with a mission to help the scholarly community take advantage of advances in technology. For more information regarding JSTOR, please contact support@jstor.org. 


\title{
Plasticity, morphology and distribution in twelve lakeshore plants
}

\author{
Scott D. Wilson
}

\begin{abstract}
Wilson, S. D. 1991. Plasticity, morphology and distribution in twelve lakeshore plants. - Oikos 62: 292-298.

The ecological significance of plasticity in twelve lakeshore plant species was investigated by examining the relationship of plasticity to growth form, competitive ability and position along an environmental gradient of soil organic matter content. Study species occupied different positions along the gradient and had a variety of growth forms, including basal rosettes, creeping graminoids, and stemmed, leafy dicots. Plasticity was measured in plants grown singly along an experimental gradient of soil organic matter content for one growing season. The degree of plasticity exhibited by a species was not significantly related to its competitive ability measured in a diallel experiment. Nor was plasticity related to position on the environmental gradient, although species of sandy soils tended to be more plastic than those of organic soils. Plasticity was significantly greater in monocots than dicots, and species differed in characters displaying plasticity along the experimental gradient. All four rosette species responded to increased soil organic matter by increasing leaf mass while holding ramet number constant, whereas other species increased ramet number. Species also differed in the direction of plastic response: root: shoot ratios had positive, negative, quadratic or non-significant relationships to the experimental gradient depending on the species considered. Because the species differed in the characters displaying plasticity, and in the strength and direction of plasticity, the most important ecological feature of phenotypic plasticity in this community may be the individuality of species responses.
\end{abstract}

S. D. Wilson, Dept of Biology, Univ. of Regina, Regina, Saskatchewan, Canada S4S $O A 2$.

The ecological significance of plasticity in plants is attracting growing attention as current theories relating morphology to distribution and community composition begin to consider phenotypic variability (Schlichting 1986, Grime et al. in press). A great deal of variation in community structure can be accounted for by environmental variation in resource availability (Grime 1979, Tilman 1988, Taylor et al. 1990), but resource availability is also one of the most important determinants of the degree and direction of plasticity (Bloom et al. 1985). Therefore, any consideration of the relationship between plant form and distribution should include plasticity.

Both growth form and resource availability can have direct effects on plasticity. Monocotyledonous species with prolific ramet production may be more plastic than dicotyledonous species which produce new ramets only after overwintering (Schlichting 1986). Plasticity may be most important in nutrient-rich habitats, where it would allow individuals to exploit temporal and spatial patches of resource richness caused by population fluctuations of competitors (Chapin 1980, Grime et al. 1986). If competition is most intense in such habitats, then high plasticity might be a component of competitive ability (Grime 1979). In contrast, plants of nutrient-poor areas might show little morphological plasticity and could react to occasional periods of nutrient abundance by increasing the biomass, but not the number, of evergreen leaves (Grime et al. 1986).

The elucidation of the ecological significance of plasticity has been limited to some extent by the small number of species included in each study. Comparisons are frequently made among populations of one species (e.g. Scheiner and Goodnight 1984), among congeners (e.g. Schlichting 1989), or among two to six species (Grime et al. 1986). Testing predictions about the rela- 
tionship of plasticity to habitat fertility or taxonomic affiliation clearly requires larger sample sizes. The objective of this study was to measure plasticity in twelve species with contrasting allocation patterns, and to determine whether plasticity was related to growth form, competitive ability and position along an environmental gradient.

\section{Methods}

\section{The study species}

Biomass allocation and plasticity were examined in twelve lakeshore plant species of varying growth forms and with different positions along a natural environmental gradient. The study species occur at the summer water line of shores of central Ontario lakes (Keddy 1983, Wilson and Keddy 1985). Horizontal variation in the distribution of lakeshore plants is related to a gradient of exposure to wave action (Pearsall 1920, Thunmark 1931, Hutchinson 1975). In central Ontario lakes, the gradient ranges from exposed, sandy shores with low soil organic matter content and nutrient concentrations to sheltered shores with high soil organic matter content and nutrient concentrations (Keddy 1983). Competition intensity increases with soil organic matter content (Wilson and Keddy 1986a) and the mean positions of the species along the gradient are related to relative competitive ability, such that dominants are found on sheltered, nutrient-rich shores and subordinates are typical of exposed, sandy beaches (Wilson and Keddy 1986b). Species richness is highest at intermediate levels of soil organic matter (Wilson and Keddy 1988). Woody and annual species are absent from this habitat, but herbaceous perennials comprise a range of growth forms from species with leaves confined to basal rosettes to taller plants with rhizomatous growth and leaves born on ascending stems.

Study species were chosen to represent a range of habitats and forms. Rosette dicots were represented by Drosera intermedia Hayne and Lobelia dortmanna L.; $D$. intermedia was the only insectivorous species in the study; rosette monocots included Eriocaulon septangulare With. and Xyris difformis Chapm.; stemless, rhizomatous monocots included Rhynchospora fusca (L.) Ait. f. and Cladium mariscoides (Muhl.) Torr.; monocots with leaves born on stems included Calamagrostis canadensis (Michx.) Beauv., Dulichium arundinaceum (L.) Britt., and Juncus pelocarpus E. Meyer.; stemmed dicots included Hypericum ellipticum Hook., Lysimachia terrestris (L.) BSP. and Triadenum fraseri (Spach) Gl. All species are perennial and their population dynamics appear to be influenced more by the production of new ramets than by establishment from seed.

To determine the mean position of each species along the exposure gradient, quadrats $(0.5 \times 0.5 \mathrm{~m}, \mathrm{n}=243)$ were placed at regular intervals along the water-line of
Axe Lake, Ontario $\left(45^{\circ} 23^{\prime} \mathrm{N}, 79^{\circ} 30^{\prime} \mathrm{W}\right)$ during $17-21$ August 1984. The presence of all species within each quadrat was noted. A soil sample $(3.5 \mathrm{~cm}$ diameter, 5 $\mathrm{cm}$ deep) was taken from the centre of the quadrat for measurement of organic matter content (Dean 1974). The mean position of each species along the exposure gradient was determined by calculating the mean soil organic matter content associated with quadrats containing the species (Wilson and Keddy 1986b).

\section{Plasticity}

Plasticity was defined as variation in biomass allocation or morphology in response to an experimental gradient of resource availability (Schlichting 1986). Biomass allocation and morphology were measured in plants grown at ten levels of soil organic matter content. Highly organic lakeshore soil was collected from five central Ontario lakes (Black Oak Lake, $45^{\circ} 30^{\prime} \mathrm{N}, 80^{\circ} 13^{\prime} \mathrm{W}$; Cardwell Lake, $45^{\circ} 20^{\prime} \mathrm{N}, 79^{\circ} 30^{\prime} \mathrm{W}$; Coldwater Lake, $45^{\circ} 00^{\prime} \mathrm{N}$, $79^{\circ} 48^{\prime} \mathrm{W}$; Deer Lake, $44^{\circ} 57^{\prime} \mathrm{N}, 7^{\circ} 27^{\prime} \mathrm{W}$; Horseshoe Lake, $\left.44^{\circ} 50^{\prime} \mathrm{N}, 79^{\circ} 38^{\prime} \mathrm{W}\right)$. The lakes were similar in size, bedrock, and absence of human disturbance. Soil was gathered in equal proportions from three sites in each lake; collection sites were highly organic shorelines in sheltered bays. Collected soil was pooled and mixed by hand for $2 \mathrm{~h}$. This produced the most organic end of the experimental gradient $(100 \%$ organic soil). The least organic end of the gradient was represented by sand obtained from a quarry $2 \mathrm{~km}$ from Coldwater Lake $(0 \%$ organic soil). Eight intermediate levels of organic matter content were formed by mixing sand and $100 \%$ organic soil to produce soils with $75,50,25,12,9,6,4$ and $2 \%$ organic soil by volume. These treatments produced a range of organic matter content $(0.80-20.7 \%$ dry soil mass lost on ignition) which spanned the range of soil organic matter content in the field over which most of the variation in species abundance occurs (Wilson and Keddy 1985). Soil for each level was mixed by hand for $1 \mathrm{~h}$ and put into $15.5 \mathrm{~cm}$ diameter watertight pots.

Approximately seventy-five individuals of each study species were collected at Axe Lake on 25 May 1982. Plants were removed from soil and stored in lake water until planting, up to $4 \mathrm{~d}$ later. Individuals of approximately equal size within each species were chosen for planting. For rosette species, an individual comprised a single ramet. Monocotyledonous species had one full ramet plus a rhizome with one or two accompanying buds planted. Dicotyledonous species had a single ramet with a portion of rhizome attached. Five individuals of each species were planted at each soil organic matter level. Each individual was grown in a separate pot in a completely randomized design. Pots were placed on flats within an outdoor exclosure at Guelph, Ontario. Potted soil was watered to saturation daily with deionized water. 


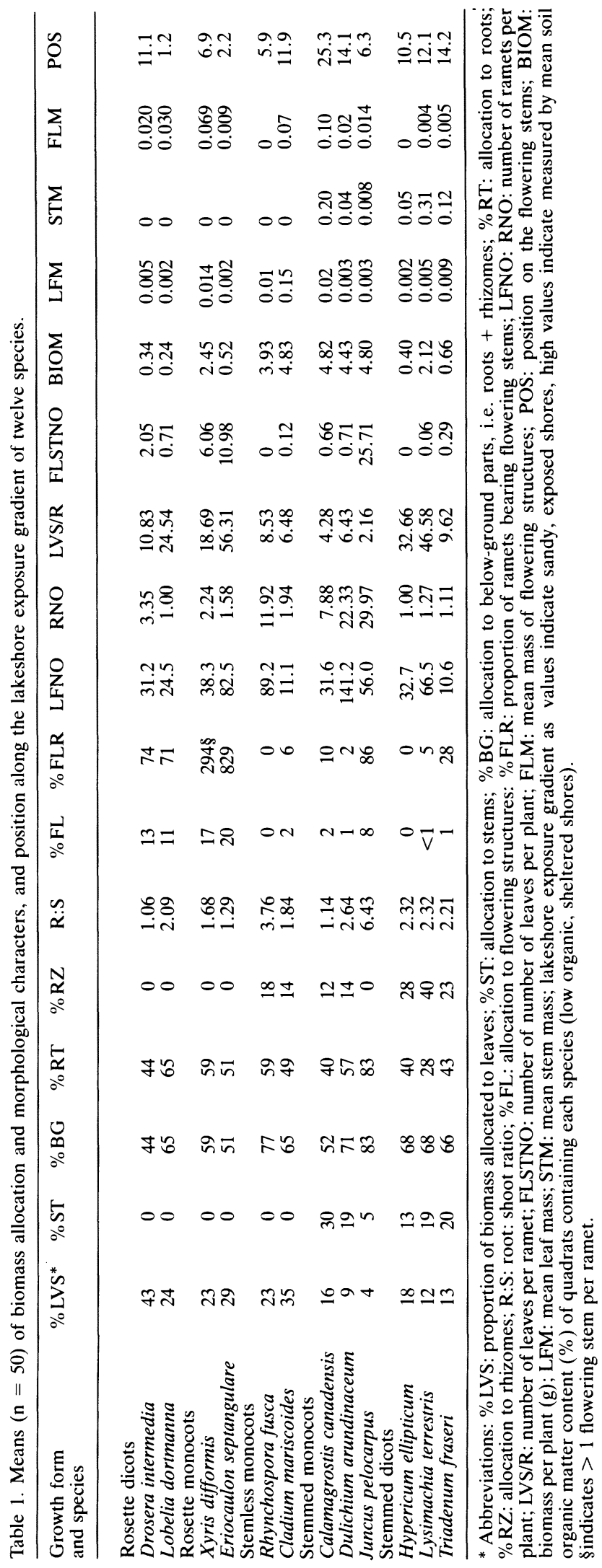

Plants were harvested over $5 \mathrm{~d}$ beginning 1 September 1982. Plants were washed, dried to constant mass at $100^{\circ} \mathrm{C}$ and sorted into leaves, stems, roots, rhizomes and flowering structures. Flowering structures included flowers, fruits, and supporting stems that did not also support leaves.

Plant parts were counted and weighed. Biomass allocation to roots, rhizomes, and roots and rhizomes combined (belowground biomass), stems, leaves and flowering structures was calculated as the proportion of total biomass. Root: shoot ratios were calculated as the ratio of all belowground biomass (roots and rhizomes) to all aboveground biomass (stems, leaves and flowers). Total biomass, proportion of ramets flowering, leaf mass, stem mass, flowering stem mass and the number of leaves per ramet were also calculated. Allocation was summarized for each species by calculating the mean of each variable across all levels of the experimental gradient. Regression analysis examined variation in allocation and morphology of each trait along the experimental gradient. Both simple and quadratic relationships were examined. Results for quadratic regressions were reported only in cases where they accounted for significantly higher proportions of variance than simple regressions (Zar 1984: 365).

Comparisons of plasticity among species were performed only for traits common to all twelve species. For example, it was not possible to compare plasticity in stem allocation of a stemmed species with that of a stemless species. Traits examined included final biomass, root: shoot ratio and leaf number. There are several methods of quantifying plasticity (Scheiner and Goodnight 1984, Schlichting 1986, Grime et al. 1986, Sultan 1987, Rice and Bazzaz 1989) but not all methods allow statistical identification of significant differences in plasticity among several species. In order to allow statistical hypothesis testing, plasticity was measured as the relative sensitivity of each species to the experimental gradient (Zuberi and Gale 1976, Falconer 1981: 123, Schlichting 1986). This was accomplished by first calculating the mean value of each trait across all twelve species at each of the ten levels of the experiment. Then, for each trait, the values for each species were regressed separately against the mean values of all twelve species. For all twelve species considered together, the value of the slope (b) of this relationship was 1. A species which was as plastic as the group as a whole had $b=1$; a species more plastic than average had $b>$ 1 ; a species less plastic had $b<1$. Slopes and $95 \%$ confidence intervals were calculated for each species using Gabriel's approximate method (Sokal and Rohlf 1981: 506; $T^{1}$ was used since $\Sigma \mathrm{x}^{2}{ }_{i}$ was identical for all comparisons). Non-overlapping confidence intervals identified species with slopes significantly different from each other. The confidence interval for the set of all species considered together was also determined in order to identify species more or less plastic than the average of the set of twelve. The plasticity analysis was 


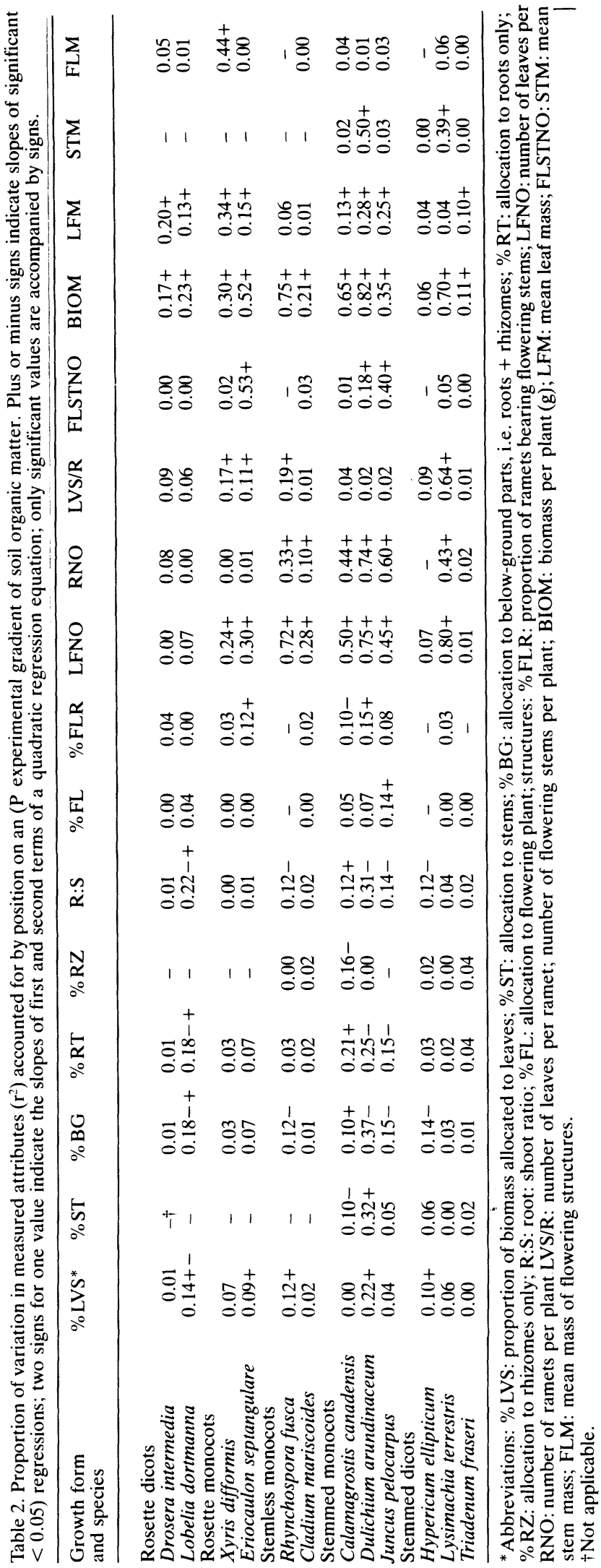

conducted on data transformed by dividing the value for each individual by the mean value for its species. This transformation standardized the different sizes of the different species and prevented large species from having greater slopes than small species simply because they had larger values for all variables (Schlichting 1986).

Relationships among allocation, plasticity and position on the exposure gradient were examined by calculating a correlation matrix using the mean of each variable for each of the set of twelve species. Proportion variables were arcsine-square root transformed and other variables were $\log 10$ transformed prior to all analyses to reduce heteroscedasticity.

The competitive abilities of seven species were measured in a field diallel experiment (Wilson and Keddy 1986b). The correlation between plasticity and competitive ability, measured as the ability of each species to grow in the presence of interspecific neighbours, was examined for Drosera intermedia, Dulichium arundinaceum, Eriocaulon septangulare, Juncus pelocarpus, Hypericum ellipticum, Lysimachia terrestris and Rhynchospora fusca.

\section{Results}

The study species represented a diverse collection of biomass allocation patterns and morphologies (Table 1). Rosette species lacked both stems and rhizomes and had much higher allocation to flowering parts $(\% \mathrm{FL})$ than all other species. Root: shoot ratios were also lower in rosette species than others, probably due to their lack of rhizomes. Leaf allocation (\%LF) was greatest in stemless species. Ramet number (RNO) at the end of the experiment ranged from one, in the case of Lobelia dortmanna, to nearly 30 in the case of Juncus pelocarpus. The mean positions (POS) of the study species along the field gradient of soil organic matter content ranged from 1.2 to $25.3 \%$.

Biomass allocation or morphology varied significantly with soil organic matter content for all twelve species (Table 2), indicating that plasticity was produced in all species by the experimental gradient. Plasticity in allocation was more marked for some traits than others. Leaf, root and belowground allocation, and root: shoot ratios were plastic in more species than were stem, rhizome or flowering part allocation. For those species showing significant responses, leaf allocation generally increased with soil organic matter content while root allocation and root: shoot ratios decreased. There were two notable exceptions to this: 1) the grass Calamagrostis canadensis showed the opposite trend;2) the rosette dicot Lobelia dortmanna showed a quadratic response: belowground allocation was minimal and aboveground allocation maximal at intermediate levels of organic matter. 

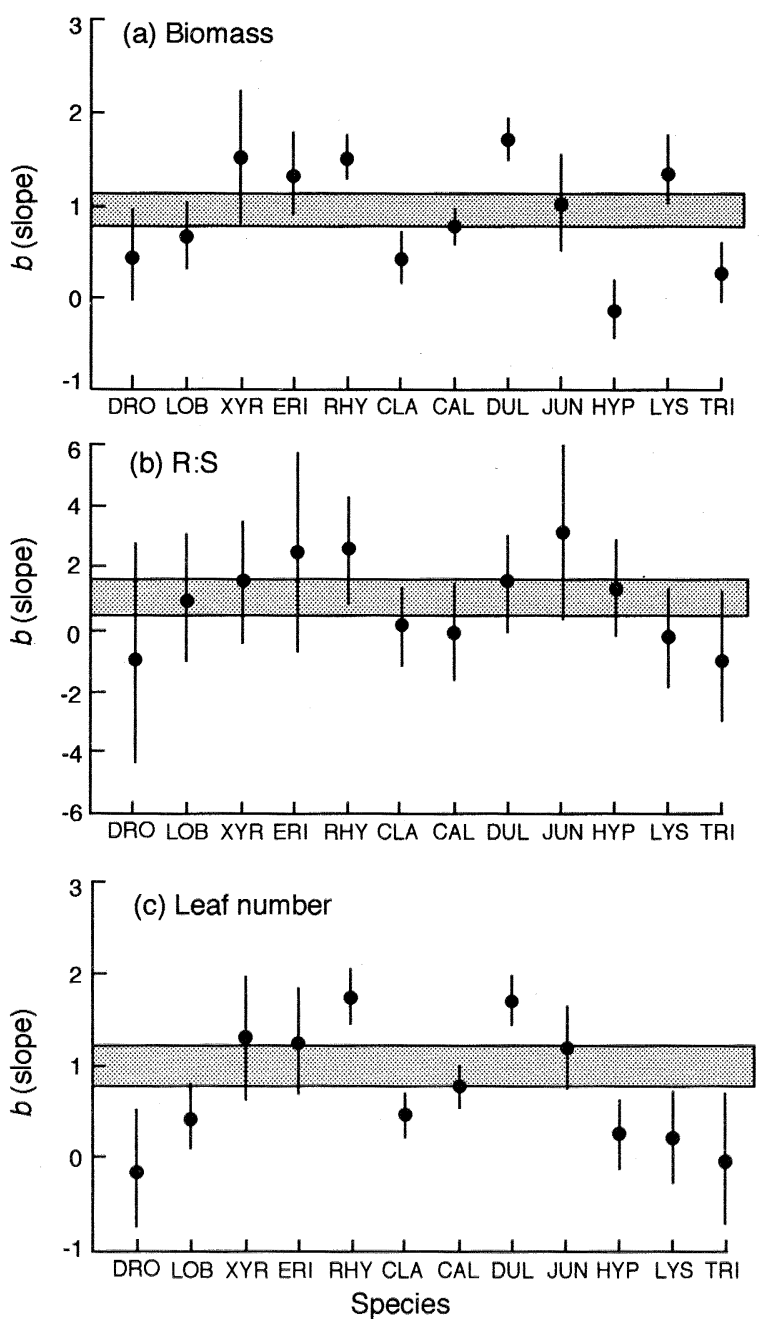

Fig. 1. Means and 95\% confidence intervals for the slopes of regression lines describing the relationship between the response of each of twelve species to an experimental gradient and the mean response for all species. Plasticity increases with slope. Species with overlapping confidence intervals are not significantly different in plasticity of a) biomass accumulation, b) root: shoot ratio, and c) leaf number. The stippled bar represents the $95 \%$ confidence interval for all species considered together. Species with confidence intervals that overlap the stippled area are not significantly different from the average for all species. Species are ranked from those occurring mostly on nutrient-poor, sandy soils (left), to nutrient-rich, organic soils (right). Species abbreviations: LOB: Lobelia dortmanna; ERI: Eriocaulon septangulare; RHY: Rhynchospora fusca; JUN: Juncus pelocarpus; XYR: Xyris difformis; HYP: Hypericum ellipticum; DRO: Drosera intermedia; CLA: Cladium mariscoides; LYS: Lysimachia terrestris; DUL: Dulichium arundinaceum; TRI: Triadenum fraseri; CAL: Calamagrostis canadensis.

Attributes displaying plasticity differed among growth forms (Table 2). Most non-rosette species increased biomass by increasing ramet number (RNO). Monocot rosettes increased biomass by increasing both leaf number (LFNO) and leaf mass (LFM), while dicot rosettes held leaf number constant but increased leaf mass.

The degree to which biomass, root: shoot ratios and leaf number was plastic in each of the twelve species was indicated by the slope of the regression equation describing the relationship between the values for an individual species and the mean value for all twelve species. Species with high slopes were more plastic than those with low slopes. Hypothesis testing for the slopes was performed by inspecting for non-overlapping Gabriel confidence intervals among the mean values of the slopes (Fig. 1). Significant differences $(\mathrm{P}<0.05)$ were found among the twelve species in the degree of their respective plasticities in biomass accumulation (Fig. 1a). Species more plastic than average were the rhizomatous monocots Rhynchospora fusca and Dulichium arundinaceum; species less plastic than average tended to be dicots. Many pairwise differences among species were evident. Species did not differ significantly in their plasticity measured as variation in root: shoot ratios (Fig. 1b). Differences in plasticity in leaf number (Fig. 1c) were similar to those for biomass. Plasticity was significantly greater than average for the monocots Rhynchospora fusca and D. arundinaceum and significantly less than average for four dicots and one monocot.

Monocots were significantly more plastic than dicots for all components examined (biomass: $\mathrm{F}=5.24, \mathrm{P}<$ 0.05 ; root: shoot: $\mathrm{F}=5.30, \mathrm{P}<0.05$; leaf number: $\mathrm{F}=$ $22.02, \mathrm{P}<0.001)$. Plasticity in biomass and leaf number increased significantly with mean leaf number $(r=0.77$, $0.76, \mathrm{P}<0.01$ ), and plasticity in leaf number was also correlated with ramet number $(\mathrm{r}=0.66, \mathrm{P}<.05)$. Plasticity of root: shoot ratios increased significantly with root allocation and with root: shoot ratios $(\mathrm{r}=$ $0.68,0.58, \mathrm{P}<0.05$ ). Plasticity did not vary significantly with any other allocation variables.

Plasticity was not significantly correlated with position along the soil organic matter gradient, but all measures of plasticity decreased with soil organic matter content $(\mathrm{r}=-0.20,-0.24,-0.57, \mathrm{P}>0.05)$. Further, plasticity tended to be greater among species of sandy shores than those of organic shores (Fig. 1). Competitive ability was not related to plasticity for any component examined (biomass: $r=0.19$; root: shoot: $r=$ 0.03 ; leaf number: $\mathrm{r}=-0.01 ; \mathrm{P}>0.05$ ).

\section{Discussion}

The study species represented a wide range of allocation patterns (Table 1), allowing comparisons of allocation and plasticity to be made for diverse growth forms. All species showed plasticity attributable to the experimental gradient in at least one character. The experiment 
was sufficiently long to allow meaningful responses to be measured since it spanned the time of highest growth rates in southern Canadian wetlands (Auclair et al. 1976). Ice formation on lakeshores renders longer experiments less relevant. There were, however, two important differences between the experimental and field gradients. First, plants in the experiment grew singly whereas those in field had neighbors and allocation may vary with the presence and identity of neighboring species (Turkington 1983, Szmeja 1987). Second, the experimental gradient incorporated only variability in soil characteristics, whereas soil organic matter on lakeshores is negatively correlated with disturbance from waves (Keddy 1983). Patterns of allocation in response to variation in disturbance can be expected to differ from those in response to variation in soil. Differences existed between experimental and field conditions, but the length of the experiment, the degree of plasticity produced, and the significant differences in allocation among the twelve species should provide robust data with which to examine relationships among plasticity, allocation and distribution.

Overall, monocots were significantly more plastic than dicots. The identity of particular traits showing plasticity varied according to growth form (Table 2). Rosette species responded to the gradient by increasing leaf biomass (LFM), but not by adjusting ramet number (RNO), indicating that these species responded to increased resource availability by hoarding photosynthate (Waller 1986). Leaf mass did not increase consistently with soil organic matter content for other species, most of which increased leaf and ramet number instead. Plastic responses differed among species (Schlichting 1986) and confirm the suggestion that rosette species of nutrient-poor sites adjust to enriched resource availability physiologically, i.e. by increasing leaf mass, whereas species of nutrient-rich habitats adjust morphologically (Grime et al. 1986). This strategy may be advantageous to species of nutrient-poor habitats because it does not commit them to maintaining new plant parts after the period of enhanced resource availability has ended. Instead of increasing intragenomic competition in time of resource shortages, this strategy allows plants simply to adjust the mass of long-lived components.

The positive correlation between plasticity and leaf number suggests that the capacity to fix carbon as determined by a species' ability to maintain and efficiently display a high number of photosynthesizing organs may be an important determinant of plasticity. Plasticity in root: shoot ratios increased significantly with root allocation and root: shoot ratios, providing further evidence that the type of plasticity varies with the identity of the species considered. In this case, species with high belowground allocation were particularly plastic in adjusting that allocation.

Plasticity was not related to position along the natural exposure gradient, although Grime (1979), Chapin (1980) and Grime et al. (1986) propose that species characteristic of nutrient-rich sites with intense competition should have relatively high plasticities. Comparisons among a few species tend to support this suggestion. A grass species characteristic of nutrient-rich habitats was more plastic than a sedge from nutrient-poor habitats (Grime et al. 1986) and the grass Agropyron repens, which dominates fertilized plots in a Minnesota old field, was more plastic than Schizachyrium scoparium, which is characteristic of unfertilized plots (Wilson and Tilman 1991). This agreement tends to disappear, however, when larger groups of species are examined, such as the eleven surveyed by Grime et al. (in press) or the twelve examined here. If anything, the consistently negative correlations between plasticity and position on the lakeshore exposure gradient and the tendency for species of sandy shores to be more plastic than those of sheltered shores (Fig. 1) suggest that plasticity might be greatest among species of unproductive sandy beaches. This result probably reflects the general preponderance of more-plastic monocots on sandy shores and less-plastic dicots on organic shores. Plasticity also was not correlated with competitive ability. Grime (1979) proposed that morphological plasticity would be important in nutrient-rich, undisturbed, competitive environments in order to allow plants to exploit temporal variation in resource availability, but the results of this study indicate that plasticity may be just as important in disturbed habitats for exploiting disturbance-induced variability in resource availability.

The study species have different field distributions but similar patterns of biomass accumulation along the experimental gradient, causing Wilson and Keddy (1985) to propose that competition may produce the differential distribution patterns observed. Examination of the allocation results, however, revealed fundamental differences among the twelve species in terms of their allocation responses to the experimental gradient (Table 2). For belowground biomass and root: shoot ratios, one species increased with soil organic matter (Calamagrostis canadensis), some decreased (Rhynchospora fusca, Dulichium arundinaceum, Juncus pelocarpus), one displayed a quadratic response (Lobelia dortmanna), and most showed no significant response. The twelve species had different patterns of allocation in spite of similar patterns of biomass accumulation. These differences indicate that responses to environmental gradients in plants grown singly may be sufficiently different to at least partially contribute to their different distributions in nature. The differences among species also underline the observation that plasticity takes different forms in different species (Grime et al. 1986, Schlichting 1986).

Acknowledgements - I am very grateful to D. Bronson, M. Misgen, D. Randall and R. Wilson for help with the experiment, to P. Keddy, D. Tilman and the Research School of Biological Sciences of the Australian National University for providing support, and to N. Fowler, P. Grime, P. Keddy, C. Nilsson and C. Zammit for greatly improving the paper. 


\section{References}

Auclair, A. N. D., Bouchard, A. and Pajaczowski, J. 1976. Plant standing crop and productivity relations in a ScirpusEquisetum wetland. - Ecology 59: 941-952.

Bloom, A. J., Chapin III, F. S. and Mooney, H. A. 1985. Resource limitation in plants - an economic analogy. Ann. Rev. Ecol. Syst. 16: 363-392.

Chapin III, F. S. 1980. The mineral nutrition of wild plants. Ann. Rev. Ecol. Syst. 11: 233-260.

Dean, W. E. 1974. Determination of carbonate and organic matter in calcareous sediments and sedimentary rocks by loss on ignition: comparison with other methods. - J. Sed. Petrol. 44: 242-248.

Falconer, D. S. 1981 Introduction to quantitative genetics. Second edition. - Longman, London.

Grime, J. P. 1979. Plant strategies and vegetation processes. Wiley, Chichester.

- , Crick, J. C. and Rincon, J. E. 1986. The ecological significance of plasticity. - In: Jennings, D. H. and Trewavas, A. J. (eds), Plasticity in plants. Company of Biologists, Cambridge, pp. 5-29.

- , Campbell, B. D., Mackey, J. M. L. and Crick, J. C. In press. Root plasticity, nitrogen capture and competitive ability. - In: Atkinson, D. (ed.), Root systems: their effect on ecosystem composition and structure.

Hutchinson, G. E. 1975. A treatise on limnology. Vol. 3. Limnological botany. - Wiley, New York.

Keddy, P. A. 1983. Shoreline vegetation in Axe Lake, Ontario: effects of exposure on zonation patterns. - Ecology 64: 331-344.

Pearsall, W. H. 1920. The aquatic vegetation of the English Lakes. - J. Ecol 7: 163-201.

Rice, S. A. and Bazzaz, F. A. 1989. Growth consequences of plasticity of plant traits in response to light conditions. Oecologia (Berl.) 78: 508-512.

Scheiner, S. M. and Goodnight, C. J. 1984. The comparison of phenotypic plasticity and genetic variation in populations of the grass Danthonia spicata. - Evolution 38: 845-855.

Schlichting, C. D. 1986. The evolution of phenotypic plasticity in plants. - Ann. Rev. Ecol. Syst. 17: 667-693.

- 1989. Phenotypic plasticity in Phlox. II. Plasticity of character correlations. - Oecologia (Berl.) 79: 496-501.
Sokal, R. R. and Rohlf, F. J. 1981. Biometry. Second edition. - Freeman, New York.

Sultan, S. E. 1987. Evolutionary implications of phenotypic plasticity in plants. - Evol. Biol. 21: 127-178.

Szmeja, J. 1987. The ecology of Lobelia dortmanna L. I. The plasticity of individuals within a constant depth interval in oligotrophic lakes. - Ekol. polska 35: 497-522.

Taylor, D. R., Aarssen, L. and Loehle, C. 1990. On the relationship between $\mathrm{r} / \mathrm{K}$ selection and environmental carrying capacity: a new habitat templet for plant life history strategies. - Oikos 58: 239-250.

Thunmark, S. 1931. Der See Fiolen und seine Vegetation. Acta Phytogeogr. Suecica 2.

Tilman, D. 1988. Plant strategies and the dynamics and structure of plant communities. - Princeton Univ. Press, Princeton, NJ.

Turkington, R. 1983. Plasticity in growth and patterns of dry matter distribution of two genotypes of Trifolium repens grown in different environments of neighbours. - Can. J. Bot. 61: 2186-2194.

Waller, D. M. 1986. The dynamics of growth and form. - In: Crawley, M. J. (ed.), Plant ecology. Blackwell, Oxford, pp. 291-320.

Wilson, S. D. and Keddy, P. A. 1985. Plant zonation on a shoreline gradient: physiological response curves of component species. - J. Ecol. 73: 851-860.

- and Keddy, P. A. 1986a. Measuring diffuse competition along an environmental gradient: results from a shoreline plant community. - Am. Nat. 127: 862-869.

- and Keddy, P. A. 1986b. Species competitive ability and distribution along a natural stress/disturbance gradient: a field experiment. - Ecology 62: 1236-1242.

- and Keddy, P. A. 1988. Species richness, survivorship and biomass accumulation along an environmental gradient. Oikos 53: 375-380.

- and Tilman, D. 1991. Components of plant competition along a productivity gradient. - Ecology 72: 1050-1065.

Zar, J.H. 1984. Biostatistical analysis. - Prentice-Hall, Englewood Cliffs, NJ.

Zuberi, M.I. and Gale, J.S. 1976. Variation in wild populations of Papaver dubium. X. Genotype-environment interaction associated with differences in soil. - Heredity 36: 359-368. 